\title{
Safety of Thyroidectomy at a rural District Hospital in Kenya
}

Ojuka D.K., MBChB, MMed Kapenguria District Hospital, P.0.Box 63 Kapenguria, Kenya, E-mail: dkinyuru@yahoo.com. Tel $+254722322246 /+254736470130$

\section{Abstract}

\section{Background}

The clinical outcome of thyroidectomy may be influenced by among other things, the experience of the surgeon performing the procedure. Furthermore, auditing of any surgical procedure helps in monitoring the safety of the procedure in the hands of the operator.

\section{Objective}

This study is an audit of outcome of thyroidectomy performed by the author within the first 18 months of qualification from a local residency program. It aims to record the outcomes as baseline to facilitate future personal and institutional trends of thyroid disease, prevalent in the area.

\section{Setting}

Kapenguria District hospital in Kenya. The author was posted to this facility immediately after completion of surgical residency at the University of Nairobi.

Design

This was a retrospective audit from April 2007 to September 2008

\section{Patients}

The patients who underwent thyroidectomy by the author from April 2007 to September 2008. The period was divided into three separate six month blocks of time (A-April to September 2007, B-October 2007 to March 2009, and C-April to September 2008.

\section{Main outcome measures}

Complications and length of stay.

Results

Thirty nine patients underwent thyroidectomy during this period. The most common type of goiter was multinodular goiter $(69.2 \%$, 27) while the most common type of surgery was total thyroidectomy $(35.9 \%, 14)$. The number of days in hospital did not differ across the periods- 1.92 for period $A, 1.75$ for $B$ and 1.07 for $C$. Two complications occurred during period $A$ and were associated with total thyroidectomy

\section{Conclusion}

Subtotal and total thyroidectomy can be safely performed by general surgeons qualifying from our local training institutions. Institutional audits are important to document future improvements in outcomes.

\section{Introduction}

Outcomes in thyroidectomy have been related to surgeon experience (in terms of the volumes operated and specialization), setting of surgery and sometimes the type of surgery (1-6). In Kenya, the bulk of thyroid surgeries are performed at district hospitals by general surgeons, often recently qualifying from residency and without the 'experience' in the terms envisaged in the literature. Previous studies have shown that general surgeons completing well-designed programs and surgical trainees in those programs can safely handle thyroidectomy with minimal complications $(7,8)$. This study sought to audit the outcome of thyroidectomy performed by a newly qualified surgeon in a rural district hospital. The baseline results will be useful for analysis of future temporal trends.

\section{Materials and methods}

A chart review of all patients who underwent thyroidectomy by the author at Kapenguria between April 2007 and September 2008 was conducted. The author was

newly qualified and posted to the district hospital in March of 2007. Kapenguria hospital is situated in West Pokot with a catchment population of about 500,000. The southern part is a mountainous terrain with 1000 $1500 \mathrm{~mm}$ rainfall per annum. The majority of the population resides in this area. The low land has low rainfall. Household iodine consumption survey conducted by the district nutritionist revealed that most households consume the required amount in the salt. The proportion of patients taking lower intakes of iodine is higher in the lower terrain.

The study period was divided into six equal months as follows: A- April 2007 to September 2007, B- October 2007 to March 2008, and C- April 2008 to September 2008.

Data on type of goiter, type of surgery, post op vocal cord status, use of drain, length of stay and complications rates were recorded. In-hospital and complications at follow-up (hematoma, laryngeal nerve palsy, and hypoparathyroidism) were recorded. Hematoma was defined as a postoperative collection of blood that required 
return to theatre for drainage. Hypoparathyroidism was defined as tetany following thyroidectomy (clinical definition since we could not measure calcium levels), laryngeal nerve palsy was defined as permanent if there was post operative change in voice that failed to resolve after 6 months as confirmed by indirect laryngoscopy at referral level.

\section{Results}

Thirty nine patients underwent thyroidectomy in this period; 12 during period A, 12 during $B$ and 15 during $C$. Most of the thyroid lesions $(32,82.1 \%)$ were due to simple (endemic) goiter. All the neoplastic goiters were benign follicular adenomas. Only three $(7.7 \%)$ lesions were toxic. The majority were clinically multinodular goiters (Figure 1). There was one temporary post operative vocal cord palsies at direct laryngoscopy during period A.

The most common operation was total thyroidectomy (14 patients, 35.9\%) (table 1). This was performed for twelve of twenty seven multinodular goiters and two of twelve solitary and diffuse goiters (Table 1 ).

A drain was used $24(61.5 \%)$ times (100\% of cases in period $\mathrm{A}$ and $40 \%$ of cases in period $\mathrm{C})(\mathrm{p}=$ $0.001)$. There was no significant influence of drain use on the length of hospital stay.

There were two complications (5.1\%). One patient developed a post-operative hematoma, and another patient experienced a transient voice change that improved in three months. Both the complications occurred during the first six months (period A). The average length of stay was 1.54 days. The mean length of stay improved from 1.92 in the first six months to 1.07 in the last six months (Figure 2).

\section{Discussion}

This audit has shown that the outcome of thyroidectomy in a district hospital under the circumstances of the study is comparable to other series. The disease pattern as shown by the diagnostic groups (multinodular goiter $69.2 \%(n=27)$, nodular goiter $23 \%(n=9)$, diffuse goiter $7.7 \%(n=3))$ is also comparable to others (10)

The complication rate of $5.1 \%$ is similar to the larger se-

\begin{tabular}{lllll} 
Type of surgery & Type of goiter & & & \\
\hline & Multinodular & Solitary nodule & Diffuse & Total \\
\hline Total & 12 & 0 & 2 & 14 \\
\hline Near Total & 11 & 0 & 1 & 12 \\
\hline Subtotal & 3 & 1 & 0 & 4 \\
\hline Lobectomy & 1 & 8 & 0 & 9 \\
\hline Total & 27 & 9 & 3 & 39 \\
\hline
\end{tabular}

Table 1: Type of goiter and choice of surgery

\begin{tabular}{llll} 
Period & Drain use & & \\
\hline & Yes & No & Total \\
\hline Period A & 12 & 0 & 12 \\
\hline Period B & 6 & 6 & 12 \\
\hline Period C & 6 & 9 & 15 \\
\hline Total & 24 & 15 & 39
\end{tabular}

Table 2:Use of drains in thyroidectomy

ries (of series > 100 cases in six years) from Maryland by Sosa et al (1). Higher complication rates (10.7-14.3\%) have been reported elsewhere $(4,8,11)$.

The average length of stay of 1.54 days is just longer than the 1.4 days reported by the Johns Hopkins researchers (1). There was no death in that study just as it was in this particular one. There are other studies with average length of stay of 2.2 -2.9 days (12), 1.8-2.5(13) and 1.72.7 days (14).

Use of drains did not influence either the hospital stay or the complication rates in this audit. The Cochrane review on use of drains in thyroidectomies in 2007(15) concluded that they are not necessary, and with continued confidence we have seen a drop in use of drains in this study as time went by.

In considering experience, it is evident from this study that as one gains experience the complications rate and average length of stay reduces. This confirms what others have noted in the literature that experience in terms of the volume of thyroidectomies one has handled will predict the outcome of his or her surgeries. 


\section{Safety of Thyroidectomy at a rural District Hospital in Kenya} Ojuka D.K.

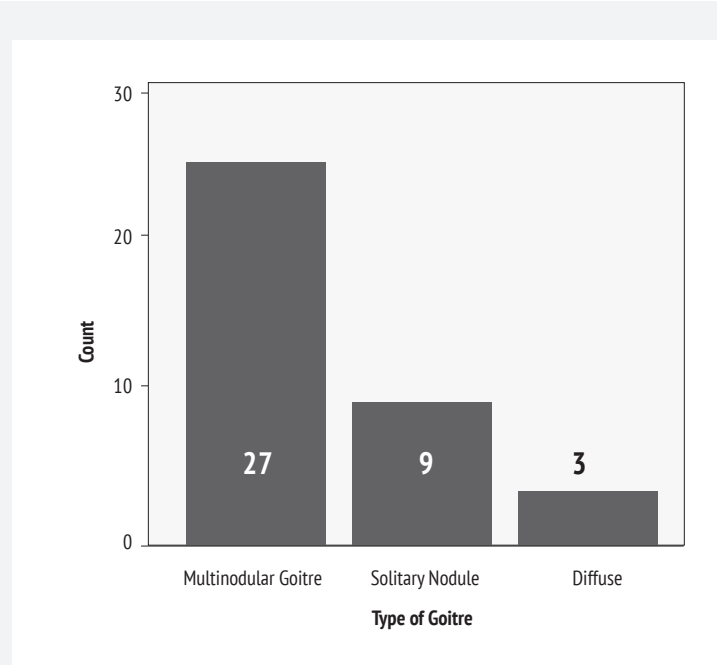

Fig 1 Type of Goitre

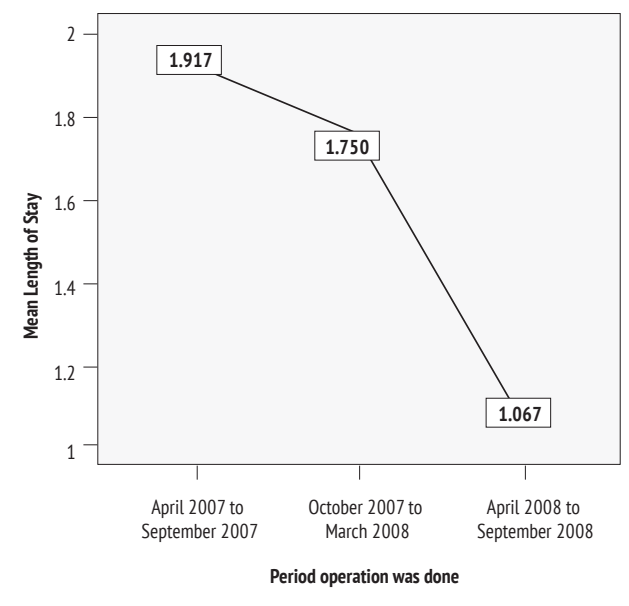

Fig 2 Mean length of stay in terms of days

Young surgeons from local residency programs can, within limits, run effective surgical programs even in the face of absent supervision. Morbidity records are useful as shown in the current audit where the serious morbidity was documented for the initial 2 patients in the first six months

This study has shown that thyroidectomies can be safely performed in our district hospitals by general surgeons who are locally trained.

\section{References}

1. Sosa JA, Bowman HM, Tielsch JM, et al. The importance of surgeon experience for clinical and economic outcomes from thyroidectomy. Ann Surg 1998 September;
228(3):320-330.

2. Mc Henry RC. Patient volumes and complications in thyroid surgery. Br J Surg 2002; 89:821-823

3. Reeve TS, Curtin A, Fingleton L, et al. Can total thyroidectomy be performed as safely by general surgeons in provincial centers as by surgeons in specialized endocrine surgical units? Making a case for surgical training. Arch Surg 1994 Aug; 129(8):834-6.

4. Richmond BK, Eads K, Flaherty S, et al. Complications of thyroidectomy and parathyroidectomy in rural community hospital setting. Am Surg 2007 Apr; 73(4):332-6.

5. Sanchez Blanco JM, Recio-Moyano G, Gomez-Rubio D et al. Influence of subspecialization in endocrine surgery outcomes of thyroidectomy in a general surgery department. Cir Esp. 2005Nov; 78(5):323-7.

6. Agada FO, King-Im JU, Atkin SL, et al. Does thyroid subspecialization alter practice and outcomes? A completed 4-year audit loop. Clin Otolaryngol 2005; 30: 48-51.

7. Mishra A, Agarwal G, Agarwal A, et al. Safety and efficacy of total thyroidectomy in hands of endocrine surgery trainees. Am J Surg 1999; 178:377-80

8. Emre AU, Cakmak GK, Tascilar O et al. Complications of total thyroidectomy performed by surgical residents versus specialist surgeons. Surg Today. 2008; 38(10): 879-85.

9. Ignjatovic M, Cuk V, Ozegovic A et al. Early complications in surgical treatment of thyroid diseases: analysis of 2100 patients. Acta Chir Iugosl 2003; 50(3):155-75.

10. Efremidou EI, Papageorgiou MS, Liratzopoulos N, et al. The efficacy and safety of total thyroidectomy in the management of benign thyroid disease: a review of 932 cases. Can J Surg 2009 Feb;52(1):39-44

11. Rosato L, Mondini G, Ginardi A, et al. Incidence of complications of thyroid surgery. Minerva Chir. 200 Oct; 55(10):693-702.

12. Sosa JA, Mehta PJ, Wang TS et al. A population-based study of outcomes from thyroidectomy in aging Americans: at what cost? J Am Coll Surg.2008 Jun;206(3):1097-105.

13. Sosa JA, Mehta PJ, Wang TS, et al. Racial disparities in clinical and economic outcomes from thyroidectomy. Ann Surg.2007 Dec; 246(6):1083-91.

14. Sosa JA, Tuggle CT, Wang TS et al. Clinical and economic outcomes of thyroid and parathyroid surgery in children. J Clin Endocrinol Metab.2008 Aug; 93(8):3058-65.

15. Samraj K, Gurusamy KS. Wound drains following thyroid surgery. Cochrane Database Syst Rev. 2007Oct 17; (4):CD006099 